\title{
The post-buckling improvement of the shape memory alloy composite plates through the active strain energy tuning using finite element method
}

\begin{abstract}
Shape memory alloy has been used as actuator parts in aerospace industry since the 1970s. In recent years, this smart material has been used to improve structural behaviours. Due to environmental heating, the problem of buckling of thin composite structures of aerospace vehicles becomes significant. A numerical study on the buckling and post-buckling improvements of composite plates due to shape memory effect behaviour of the shape memory alloy is presented. The shape memory alloy wires were embedded within laminated composite plates to exploit the recovery stress induced by the shape memory alloy to improve the stiffness of the plates. The study was conducted on symmetric and anti-symmetric angleply and cross-ply composite plates. The methods of active property tuning and active strain energy tuning were applied to show the various effects of the shape memory alloy on the studied behaviours. A geometric non-linear finite element model of the shape memory alloy composite plates and its source code were developed. It was found that significant improvements occurred in the critical loads and the post-buckling paths of the symmetric and anti-symmetric angle-ply and the symmetric cross-ply composite plates due to the active strain energy tuning method. In the case of the anti-symmetric cross-ply composite plate where bifurcation point did not exist, the post-buckling path improved substantially too.
\end{abstract}

Keyword: Shape memory alloy; Active strain energy tuning; Non-linear finite element model; Post-buckling 